1 nearly 1,000 dentists leaving NHS services in the last year.

BDA Chair Eddie Crouch said: 'every new colleague unable to sit this exam translates into thousands of patients that will be denied access to needed care.

'Inaction has left highly skilled clinicians waiting tables and stacking shelves while millions struggle to get an NHS appointment.

'For the sake of our patients, government must ensure that these dentists are supported and those still waiting to sit the exams can look forward to a fairer system?

\section{Notice of death}

David Boswell studied dentistry at Guy's Hospital from 1945 and practised as a dentist from 1951 in the Bath/Midsomer Norton area. David died at home in Timsbury surrounded by his family on 1 February 2022. Loving husband, father, grandfather and great-grandfather.

His funeral service was held in Timsbury, near Bath, earlier in February. Donations to Dorothy House and Smile Train.

\title{
Research to examine the role dentists can play in tackling obesity crisis
}

A new study being led by Loughborough University will look at the role dentists can play in reducing obesity in the UK.

Over $50 \%$ of the global population are living with being overweight and are at increased risk of developing diseases such as type 2 diabetes, heart disease and cancer.

GPs and practice nurses have for some time used their patient consultations to raise the subject of weight management. But despite dentists already delivering behaviour change messages for oral health during their consultations - for example smoking cessation and reducing the consumption of sugar sweetened beverages - the role they can play in tackling obesity has so far been overlooked.

Now researchers from Loughborough will be working directly with dentists to assess how they can provide weight management interventions to their patients.

It will look at what can be learnt from the NHS Making Every Contact Count campaign, providing training for dentists on how to have constructive conversations about weight management with their patients.

The study is being led by Amanda Daley, a Professor of Behavioural Medicine based in the university's Centre for Lifestyle Medicine and Behaviour (CLiMB).

Professor Daley said: 'the case for dentists to be involved in reducing population obesity is strong. Like GPs, dentists are part of primary care health services and are ideally positioned to screen and intervene to reduce obesity.

'They typically consult with most of the population at least yearly, meaning they could routinely embed efficient monitoring of weight into dental health services and offer interventions at scale to both adults and children.

'If we are serious about reducing obesity in the population, it will require an "all hands-on deck" approach, including active advocacy from dental health professionals.'

Jessica Large, a dentist working with the project team, said: 'it is important that we look at how all health professionals are able to contribute to reducing obesity in the public and dentists might be able to help in a positive way to achieve this.

'Routine body mass index screening for children and healthy weight discussions are already ongoing in some hospital dental

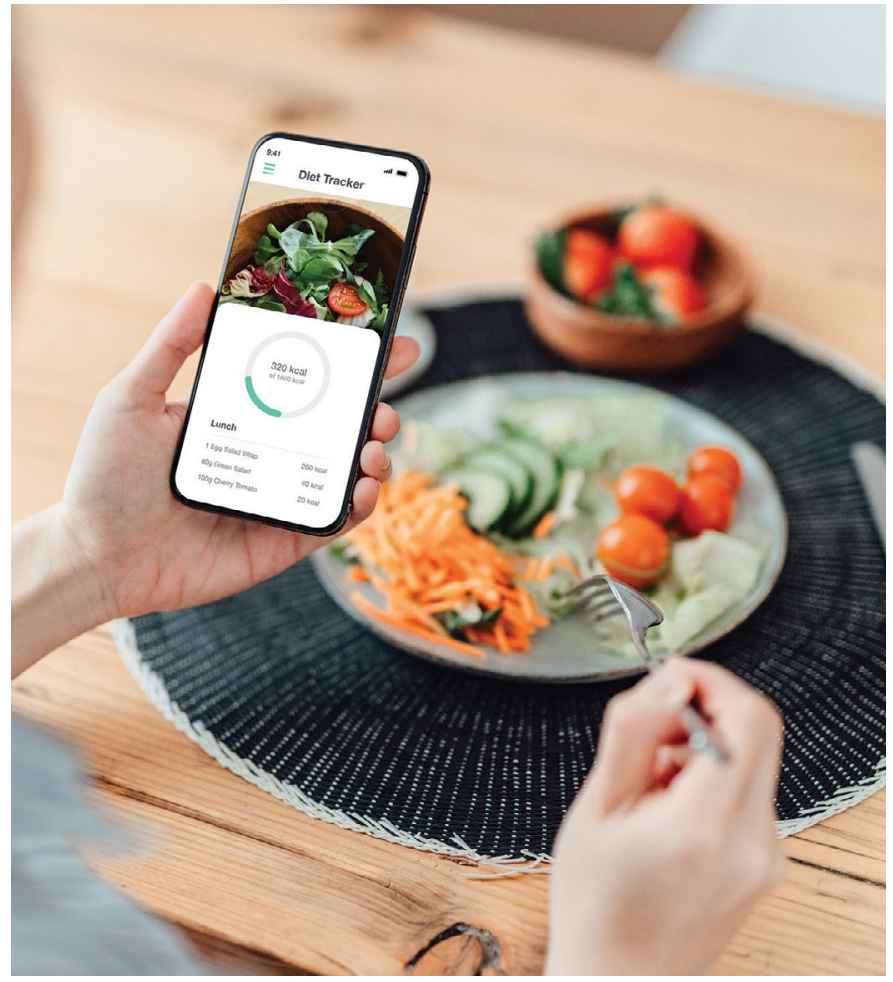

settings, with positive feedback from families and dental teams. I am looking forward to exploring the wider acceptability amongst the profession and public.'

The research is being funded via the National Institute for Health Research Research Professorship programme and will run for two years. Any dentists interested in being part of the project should contact the CLiMB team at climb@lboro.ac.uk.

Professor Daley has published an opinion piece on the role dentists have to play in tackling obesity in the BDJ: 'Time to get our teeth into reducing obesity: should dentists screen and deliver interventions to reduce obesity in the population? ${ }^{1}$

\section{Reference}

1. Daley A J. Time to get our teeth into reducing obesity: should dentists screen and deliver interventions to reduce obesity in the population? Br Dent J 2022; 232: 78-79. 